NERS: Jurnal Keperawatan, Volume 16, No. 1, Maret 2020, (Hal. 1-9)

\title{
Efikasi Diri Anak Usia 6-18 Tahun yang Mengalami Thalasemia
}

\section{Stella Pramasita Arundina ${ }^{a}$, Lina Dewi Anggraeni ${ }^{b}$, Paramitha Wirdani Ningsih Marlina $^{c}$}

\author{
aMahasiswa S1 Keperawatan STIK Sint Carolus, Jalan Salemba Raya No. 41, Jakarta Pusat, \\ 10440, Indonesia \\ ${ }^{b}$ Dosen STIK Sint Carolus, Jalan Salemba Raya No. 41, Jakarta Pusat dan 10440, Indonesia \\ 'Dosen STIK Sint Carolus, Jalan Salemba Raya No. 41, Jakarta Pusat dan 10440, Indonesia \\ e-mail korespondensi: pramasitastella@yahoo.co.id
}

\begin{abstract}
Thalassemia patient should undergo a repeated treatment, so it causes side effects on his health both physically and psychologically.The most common psychological problem suffered by the patient is the decreasing of self efficacy which affects the attitude and mindset of children with thalassemia.The purpose of this research is to find out the 6-18 years old children self efficacy portrayal with thalassemia on hospital X, West Jakarta. The research design used in this research was quantitative descriptive and cross sectional approach and questionnaire with interview as the instruments. The sampling technique used is total sampling with the number of sample of 50 children, conducted on January 2019. The data analyses used were shapiro wilk normality test and frequency distribution test. The result showed that $62 \%$ including 6-12 years with $60 \%$ female sex, respondents who underwent therapy <10 years as much as $52 \%$ with early age diagnosed at $<1$ year as much as 38\%. Self efficacy was high in the 13-18 year age group as much as 63.2\%, self-efficacy on the general aspects in the 6-12 year age group (58.1\%) and 1318 years old (57.9\%) were categorized good, self efficacy on the aspects of strength in the 6-12 year age group (74,2\%) and 13-18 year old (73,7\%) were categorized good and a high selfefficacy on the aspect of level in the 13-18 year age group as much as 63,2\%.It is recommended that children with thalassemia can control their self efficacy every day as an effort to maintain their health.
\end{abstract}

Keywords: self efficacy, thalassemia. 
NERS: Jurnal Keperawatan, Volume 16, No. 1, Maret 2020, (Hal. 1-9)

\begin{abstract}
Abstrak
Penderita thalasemia harus menjalani pengobatan secara berulang, sehingga menyebabkan efek samping pada kesehatannya baik secara fisik dan psikis. Permasalahan psikis yang sering dialami adalah penurunan efikasi diri yang mempengaruhi sikap dan pola pikir anak dengan thalasemia.Tujuan penelitian untuk mengetahui gambaran efikasi diri anak usia 6-18 tahun dengan thalasemia di Rumah Sakit X, Jakarta Barat. Desain penelitian menggunakan deskriptif kuantitatif dengan pendekatan cross sectional dan instrumen berupa kuesioner dengan wawancara. Teknik sampling yang digunakan adalah total sampling dengan jumlah sampel sebanyak 50 anak, dilakukan pada bulan Januari 2019. Analisis data menggunakan uji normalitas saphiro wilk dan uji distribusi frekuensi. Hasil penelitian menunjukkan sebanyak $62 \%$ tergolong usia 6-12 tahun dengan jenis kelamin perempuan sebanyak $60 \%$, responden yang menjalani terapi $<10$ tahun sebanyak $52 \%$ dengan usia awal terdiagnosis pada usia $\leq 1$ tahun sebanyak $38 \%$. Efikasi diri tinggi pada kelompok usia 13-18 tahun sebanyak 63,2\%, efikasi diri aspek general pada kelompok usia 6-12 tahun $(58,1 \%)$ dan $13-18$ tahun $(57,9 \%)$ sudah tergolong baik, efikasi diri aspek strength pada kelompok usia 6-12 tahun (74,2\%) dan 13-18 tahun (73,7\%) sudah tergolong baik dan efikasi diri tinggi dalam aspek level yaitu pada kelompok usia 13-18 tahun sebanyak 63,2\%. Disarankan agar anak dengan thalasemia dapat mengontrol efikasi diri dalam kehidupan sehari-hari sebagai salah satu usaha untuk mempertahankan kondisi kesehatannya.
\end{abstract}

Kata kunci: Efikasi diri, thalasemia.

\section{PENDAHULUAN}

Thalasemia merupakan anemia yang terjadi akibat sel-sel darah merah mati lebih cepat daripada kecepatan sumsum tulang dalam memproduksi sel darah merah. Produksi hemoglobin $(\mathrm{Hb})$ akan menjadi berkurang dan sel darah merah mudah rusak. Sel darah merah yang normal berumur 120 hari sedangkan pada penderita thalasemia sel darah merah mengalami umur yang lebih pendek $(<120$ hari).

Angka kejadian thalasemia tertinggi didunia yaitu India 100.000 penderita, Thailand 35.000 penderita,dan Bangladesh 6.880 penderita. Indonesia ada diperingkat keempat tertinggi di dunia yaitu sebanyak 5.000 penderita thalasemia. Angka kelahiran dengan kelainan gangguan hemoglobin di dunia diperkirakan 300.000, dimana sekitar 60.000-70.000 adalah penderita thalasemia mayor.

Indonesia menjadi salah satu negara dengan angka kejadian thalasemia yang tinggi. Berdasarkan data dari Lembaga Eijkman angka kejadian thalasemia alpa di Indonesia sekitar 2,6\%-11\%, banyak ditemukan di Pulau Sulawesi, pada suku Bugis atau suku Kajang. Thalasemia beta, dengan pembawa sifat terbanyak ditemukan di Pulau Sumatera, dan sekitar hampir $10 \%$ di daerah Palembang. Anak dengan thalasemia akan terus menerus menjalani terapi pengobatan dan tranfusi darah secara berulang.Pengobatan tersebut dapat menyebabkan beberapa efek samping secara fisik dan psikososialnya.Secara psikososial penderita akan mengalami penurunan efikasi diri sehingga mempengaruhi cara berpikir, reaksi, emosi dan perilaku.Tanda gejala yang dialami juga menyebabkan mereka berpikir bahwa mereka berbeda, menjadi rendah diri, cemas, takut dan malu.

Seseorang yang memiliki efikasi diri yang tinggi, maka persepsinya dalam melakukan segala sesuatu akan berhasil yang artinya ia percaya bahwa ia dapat mengandalkan drinya sendiri, tetapi sebaliknya bila seseorang tersebut memiliki efikasi diri yang rendah maka efikasi dirinya juga minim sehingga hal yang ingin ia capai tidak dapat dikerjakan secara maksimal.

Penelitian yang telah dliakukan oleh peneliti lain didapatkan hasil bahwa dilihat 
dari aspek fisik berkaitan dengan penyakit dan aktifitas berada pada tingkat rendah sebanyak $49,2 \%$ dengan menunjukkan bahwa sebagian responden hampir kesulitan dalammelakukan aktifitas seharihari dan merasa lemah. Aspek emosi sebanyak $60,3 \% \quad$ mengalami perasaantakut, cemas marah dan sedih. Pada aspek sosial sebanyak $60,3 \%$ berada pada tingkat tinggi yang menunjukkan bahwa sebagian besar responden juga tidak selalu mengalami kesulitan bergaul dan tidak diejek. Pada aspek sekolah sebanyak54,0\% menunjukkan bahwa responden merasa kesulitan konsentrasi pada saat jam pelajaran

Penelitian dari peneliti lain yang dilakukan dengan 5 responden berdasarkan hasil wawancara menunjukkan bahwa sebagian besar responden tidak memiliki kesulitan dalam bergaul serta medapatkan dukungan dari keluarga dan teman-temannya meskipun terbatas dalam beraktifitas.

Oleh sebab itu penelitian ini bertujuan untuk mengidentifikasi efikasi diri anak usia 6-18 tahun dengan thalasemia yang dilihat dari berbagai aspek. Penelitian ini belum mengembangkan lebih lanjut apa saja faktor-faktor yang mempengaruhi efikasi diri anak thalasemia dan hubungan efikasi diri yang dipengaruhi oleh pengalaman keberhasilan diri, persuasi verbal, keadaan psikologis dan emosional pada anak thalasemia.

\section{METODE}

Penelitian ini berlangsung mulai bulan Januari 2019 sampai bulan Mei 2019. Penelitian ini menggunakan pendekatan cross sectional dengan desain deskriptif kuantitatif.Instrumen dalam penelitian ini yaitu kuesioner yang dibuat oleh peneliti danwawancara. Teknik sampling penelitian yang digunakan adalah total sampling dengan analisis data menggunakan uji saphiro wilk dan uji distribusi frekuensiyang diteliti, diantaranya usia, jenis kelamin, lama terapi, usia awal terdiagnosis dan efikasi diri. Sampel penelitian ini berjumlah 50 anak dengan thalasemia yang rutin melakukan tranfusi darah di Rumah Sakit X Jakarta Barat. Penelitian ini telah mendapatkan ethical approval dari Komisi Etik Fakultas Kedokteran Universitas Indonesia dengan nomor: 1285/UN2.FI/ETIK/2018.

Pengumpulan data pada penelitian ini melalui beberapa tahapan yaitu : mengajukan surat permohonan ijin dari institusi, menyerahkan surat permohonan ijin yang dikeluarkan oleh institusi kepada bagian diklat dan kepala ruang bagian uji valid di RS X Jakarta Pusat, setelah mendapat ijin peneliti melakukan uji valid dan terlebih dahulu menjelaskkan tujuan dan prosedur yang akan dilakukan, dan setelah selesai peneliti mengolah data dengan SPSS 22. Bila data dinyatakan valid dan reliabel maka kuesioner siap diberikanpada responden yang sebenarnya.

Tahapan pengumpulan data pada penelitian yaitu : mengajukan surat permohonan ijin dari institusi, menyerahkan surat permohonan ijin yang dikeluarkan oleh institusi kepada bagian diklat dan kepala ruang bagian penelitian di RS X Jakarta Barat, setelah mendapat ijin peneliti menjelaskkan tujuan dan prosedur yang akan dilakukan serta memperkenankan responden untukmembaca pernyataan, bila bersedia responden akan menandatangani surat persetujuan dan responden diberi kesempatan bertanya apabila ada pernyataan yang belum dimengerti, setelah responden mengisi semua pernyataan pada kuesioner peneliti mengumpulkan dan mengolah data dengan SPSS menjadi data penelitian.

Hasil uji validitas dari kuesioner yang terdiri dari aspek strength, aspek leveldan aspek general.Dalam penelitian ini menunjukkan bahwa nilai table $\mathrm{R}=0$, 3610 , aspek strength didapatkan nilai tabel $\mathrm{R}=0,3610$, aspek level didapatkan nilai 
NERS: Jurnal Keperawatan, Volume 16, No. 1, Maret 2020, (Hal. 1-9)

tabel $\mathrm{R}=0,3610 \mathrm{dan}$ aspek general didapatkan nilai tabel $\mathrm{R}=$ 0,3610.Sedangkan, uji reliabilitas mendapatkan hasil yaitu efikasi diri didapatkan nilai $\alpha$ cronbach 0,872 , aspek strength didapatkan nilai $\alpha$ cronbach 0,811 , aspek level didapatkan nilai $\alpha$ cronbach 0,742 dan aspek general didapatkan nilai $\alpha$ cronbach 0,620.Peneliti melakukan analisis data menggunakan aplikasi SPSS 22 (Statistical Package for Social Science)

\section{HASIL}

Tabel 5.1 Distribusi Data Demografi Anak dengan Thalasemia

\begin{tabular}{clll}
\hline No & \multicolumn{1}{c}{ Variabel } & $\mathrm{f}$ & $\%$ \\
\hline 1 & Usia & & \\
& $-\quad 6-12$ tahun & 31 & 62 \\
& $-\quad 13-18$ tahun & 19 & 38 \\
\hline 2 & JenisbKelamin & & \\
& $-\quad$ Laki-laki & 20 & 40 \\
& $-\quad$ Perempuan & 30 & 60 \\
\hline 3 & Lama Terapi & & \\
& $-\quad<10$ tahun & 26 & 52 \\
& $-\quad \geq 10$ tahun & 24 & 48 \\
\hline & Total & 50 & 100 \\
\hline
\end{tabular}

Berdasarkan tabel dapat diketahui bahwa sebanyak 31 anak (62\%) adalah usia 6-12 tahun. Selanjutnya, dapat diketahui bahwa dari 50 anak dengan thalasemia yang diteliti sebanyak 30 responden $(60 \%)$ berjenis kelamin perempuan. Selanjutnya, diketahui juga bahwa sebanyak 26 responden (52\%) sudah menjalan iterapi selama kurang dari 10 tahun.

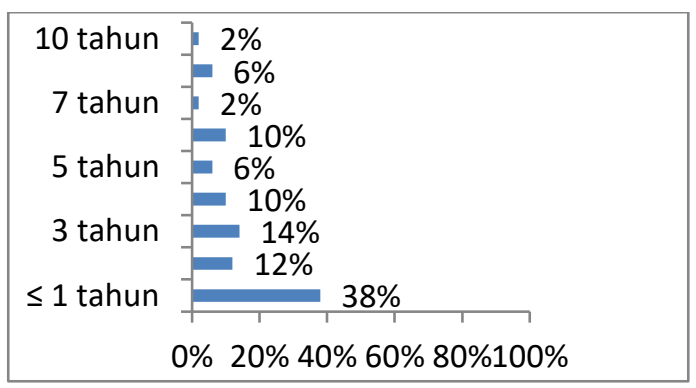

Gambar 5.2 Distribusi frekuensi berdasarkan usia awal terdiagnosis anak dengan thalasemia

Distribusi usia awal terdiagnosis anak dapat diketahui bahwa dari 50 anak dengan thalasemia, ada 19 anak (38\%) yang usia awal terdiagnosisnya pada usia kurang atau sama dengan 1 tahun, 6 anak (12\%) awal terdiagnosis pada usia 2 tahun, dan 7 anak (14\%) awal terdiagnosis pada usia 3 tahun.

Tabel 5.3 Distribusi frekuensi berdasarkan efikasi diri pada anak dengan thalasemia

\begin{tabular}{|c|c|c|c|c|c|c|}
\hline \multirow[t]{3}{*}{ Usia } & \multicolumn{4}{|c|}{ Efikasidiri } & & \multirow[t]{2}{*}{ Total } \\
\hline & \multicolumn{2}{|c|}{ Tinggi } & \multicolumn{2}{|c|}{ Rendah } & & \\
\hline & $\mathrm{N}$ & $\%$ & $\mathrm{~N}$ & $\%$ & $\mathrm{~N}$ & $\%$ \\
\hline $\begin{array}{c}\text { 6-12 } \\
\text { tahun }\end{array}$ & 16 & 51,6 & 15 & 48,4 & 31 & 100 \\
\hline $\begin{array}{l}13-18 \\
\text { tahun }\end{array}$ & 12 & 63,2 & 7 & 36,8 & 19 & 100 \\
\hline Total & 26 & 52 & 24 & 48 & 50 & 100 \\
\hline
\end{tabular}

Distribusi frekuensi berdasarkan efikasi diri diperoleh data bahwa efikasi diri pada kelompok usia 13-18 tahun sebanyak 12 responden $(63,2 \%)$ memiliki efikasi diri yang tinggi

Tabel 5.4 Distribusi frekuensi berdasarkan efikasi diri aspek general pada anak dengan thalasemia

Usia Efikasi diri aspek general Total


NERS: Jurnal Keperawatan, Volume 16, No. 1, Maret 2020, (Hal. 1-9)

\begin{tabular}{ccccccc}
\multicolumn{2}{c}{ Tinggi } & \multicolumn{2}{c}{ Rendah } \\
\hline & $\mathrm{N}$ & $\%$ & $\mathrm{~N}$ & $\%$ & $\mathrm{~N}$ & $\%$ \\
\hline $\begin{array}{c}6-12 \\
\text { tahun }\end{array}$ & 18 & 58,1 & 13 & 41,9 & 31 & 100 \\
$\begin{array}{c}13-18 \\
\text { tahun }\end{array}$ & 11 & 57,9 & 8 & 42,1 & 19 & 100 \\
\hline Total & 26 & 52 & 24 & 48 & 50 & 100 \\
\hline
\end{tabular}

Distribusi frekuensi berdasarkan efikasi diri dalam aspek general (penguasaan diri) diperoleh data bahwa usia $6-12$ tahun sebanyak 18 responden $(58,1 \%)$ dan usia 13-18 tahun sebanyak 11 responden $(57,9 \%)$ memiliki efikasi diri yang tinggi.

Tabel 5.5 Distribusi frekuensi

berdasarkan efikasi diri aspek strength pada anak dengan thalasemia

\begin{tabular}{ccccccc}
\hline Usia & \multicolumn{4}{c}{$\begin{array}{c}\text { Efikasi diri aspek } \\
\text { strenght }\end{array}$} & & Total \\
& \multicolumn{2}{c}{ Tinggi } & \multicolumn{2}{c}{ Rendah } & & \\
\hline & $\mathrm{N}$ & $\%$ & $\mathrm{~N}$ & $\%$ & $\mathrm{~N}$ & $\%$ \\
\hline $\begin{array}{c}6-12 \\
\text { tahun }\end{array}$ & 23 & 74,2 & 8 & 25,8 & 31 & 100 \\
$\begin{array}{c}13-18 \\
\text { tahun }\end{array}$ & 14 & 73,7 & 5 & 26,3 & 19 & 100 \\
\hline Total & 37 & 74 & 13 & 26 & 50 & 100 \\
\hline
\end{tabular}

Distribusi frekuensi berdasarkan efikasi diri dalam aspek strenght (kekuatan diri) diperoleh data bahwa usia $6-12$ tahun sebanyak 23 responden $(74,2 \%)$ dan usia 13 - 18 tahun sebanyak 14 responden $(73,7 \%)$ memiliki efikasi diri yang tinggi.

Tabel 5.6 Distribusi frekuensi berdasarkan efikasi diri aspek level pada anak dengan thalasemia

\begin{tabular}{ccccccc}
\hline Usia & \multicolumn{3}{c}{$\begin{array}{c}\text { Efikasi diri aspek level } \\
\text { Tinggi }\end{array}$} & \multicolumn{2}{c}{ Rendah } & \\
& $\mathrm{N}$ & $\%$ & $\mathrm{~N}$ & $\%$ & $\mathrm{~N}$ & $\%$ \\
\hline $\begin{array}{c}6-12 \\
\text { tahun }\end{array}$ & 17 & 54,8 & 14 & 45,2 & 31 & 100 \\
$\begin{array}{c}13-18 \\
\text { tahun }\end{array}$ & 12 & 63,2 & 7 & 36,8 & 19 & 100 \\
\hline Total & 29 & 58 & 21 & 42 & 50 & 100 \\
\hline
\end{tabular}

Distribusi frekuensi berdasarkan efikasi diri dalam aspek level (tingkatan kesulitan) diperoleh data bahwa kelompok usia 13-18 tahun sebanyak 12 responden $(63,2 \%)$ memiliki efikasi diri yang tinggi pada aspek level.

\section{PEMBAHASAN}

Penderita thalasemia lebih banyak ditemukan di usia 6-12 tahun dengan gejala yang sudah mulai nampak yaitu pucat, lemas serta gejala lainnya. Hasil penelitian lainnya menyatakan bahwa di RSUD Arifin Achmad menyatakan bahwa mayoritas anak thalasemia berada pada rentang usia 6-11 tahun (44,6\%). Hasil penelitian ini juga didukung oleh hasil penelitian lain yang menyatakan bahwa rentang usia paling banyak yaitu 6-13 tahun $(51,3 \%)$. Sejalan dengan penelitian lain bahwa dari 30 anak penderita thalasemia, 18 anak (60\%) berjenis kelamin perempuan

Distribusi jenis kelamin pada penderita thalasemia tidak menunjukkan perbedaan presentase yang signifikan dikarenakan bahwa thalasemia merupakan penyakit genetik yang diturunkan secara autosoma resesif.Data tersebut didukung dengan pernyataan bahwa berdasarkan hukum Mendel bila kedua pasangan pembawa sifat thalasemia/minor menikah maka kemungkinan yang terjadi mereka mempunyai $25 \%$ anak yang sehat, $50 \%$ anak sebagai pembawa sifat/minor, dan $25 \%$ anak sebagai penderita thalasemia/mayor.

Thalasemia merupakan penyakit kronis yang memungkinkan penderitanya mengalami keadaan sakit baik fisik, psikologis atau kognitif yang menyebabkan keterbatasan dan membutuhan perawatatan yang intensif di rumah sakit maupun dirumah. Lamanya menderita penyakit pada anak dengan thalasemia tergantung dari kapan terdiagnosa menderita thalasemia, semakin awal terdiagnosa maka semakin lama penderita tersebut menderita thalasemia sesuai dengan usianya saat ini.

Perawatan yang lebih memungkinkan bagi penderita thalasemia untuk hidup lebih lama yaitu dengan menjalani tranfusi, namun tranfusi secara berulang juga dapat 
NERS: Jurnal Keperawatan, Volume 16, No. 1, Maret 2020, (Hal. 1-9)

menyebabkan komplikasi yang dapat berpengaruh pada aktifitas fisik bahkan tumbuh kembang penderitanya. Hal ini didukung juga dari hasil wawancara yang dilakukan pada anak yang menderita thalasemia dimana diketahui bahwa tranfusi menjadi hal yang sudah biasa dan harus dijalani setiap bulan hingga bertahun-tahun, anak menjadi lebih mengerti dalam memelihara kondisi kesehatannya. Anak mengatakan bahwa terkadang memaksakan diri dalam melakukan aktifitas sehingga kondisi kesehatannya menjadi tidak stabil.

Thalasemia mayor secara klinis terlihat jelas pada usia 3-6 bulan yaitu nampak anemia dengan hb 2-6 g/dl. Berdasarkan hasil wawancara yang dilakukan dengan sebagian ibu yang memiliki anak dengan thalasemia diketahui bahwa sebelum anaknya terdiagnosis thalasemia pada usia $<1$ tahun anak mengalami pucat, demam berhari-hari, mual, muntah. Ibu responden mengatakan bahwa mereka tidak langsung membawa anaknya ke fasilitas kesehatan untuk pemeriksaan lebih lanjut karena kurangnya pengetahuan orang tua terkait tanda dan gejala tersebut.

Efikasi diri diperlukan bagi penderita dengan penyakit kronis untuk membantu meningkatkan kepercayaan diri dalam proses penderita menjalani pengobatan yang menahun.

Berdasarkan data, anak yang memiliki efikasi diri yang tinggi akan lebih mampu menguasai diri untuk dapat bersosialisasi, tekun berusaha, dan percaya diri dengan kemampuannya dalam menyelesaikan tugas sekolah meskipun dengan keterbatasan kondisi yang dialami. Efikasi diri pada setiap individu akan berbeda satu dengan yang lainnya berdasarkan 3 aspek. Hal ini dapat dilihat dari aspek general, level dan strength.

Data menunjukkan bahwa efikasi diri kelompok usia 13-18 tahun lebih tinggi dari kelompok usia 6-12 tahun. Pada usia tersebut perkembangan remaja terkait pola pikir dan tingkah laku akan berkembang menjadi lebih dewasa. Di usia tersebut efikasi diri pada remaja sudah semakin terbentuk, sehingga akan berpikir kritis dalam menentukan perilakunya untuk menghadapi situasi yang sulit.

Semakin bertambahnya usia, maka akan semakin banyak pengalaman atau pembelajaran yang sudah dijalani. Namun, untuk memiliki efikasi diri yang baik tergantung bagaimana individu tersebut menyikapi serta mengambil setiap pengalamannya agar dapat menjadi hal positif bagi individu. Apabila individu mampu dengan baik menyikapi dan mau berusaha belajar dari pengalamannya, maka efikasi diri yang baik dapat terwujud.

Meskipun penderita thalasemia terbatas dengan kondisi kesehatannya, namun dapat dilihat bahwa mereka sudah baik dalam menguasai diri mereka ketika bersosialisasi atau saat dihadapkan pada situasi yang sulit mereka tetap mencoba untuk dapat melakukan kegiatan belajar dan bermain seperti anak normal seusianya. Kedua kelompok usia tergolong baik di dalam efikasi diri pada aspek general (penguasaan diri).

Didukung oleh penelitian lain yang menyatakan bahwa sebanyak $75,1 \%$ penderita thalasemia sudah mengalami manajemen yang baik secara internal ataupun eksternal sehingga kondisi kronis yang dialaminya membuat individu merasa nyaman dan mampu beradaptasi pada keadaan. Hal tersebut didukung oleh penelitian lainnya yang mengungkapkan bahwa 3 dari 5 respondennya tidak mengalami kesulitan dalam bersosialisasi dengan teman atau di lingkungan dikarenakan dukungan keluarga yang menumbuhkan motivasi kepercayaan diri mereka.

Berdasarkan dari hasil observasi, Rumah Sakit X mampu menciptakan lingkungan yang baik hal itu terlihat saat anak satu dengan yang lainnya dapat berinteraksi saling mengenal selama sedang menjalani transfusi. Peran dari perawat dan para orang tua di ruang tersebut menunjukkan sikap mendukung dan ramah, sehingga dapat membantu membentuk penguasaan diri yang baik dalam hal interaksi bagi penderita thalasemia. Faktor lingkungan juga dapat mempengaruhi perkembangan penguasaan diri individu. 
NERS: Jurnal Keperawatan, Volume 16, No. 1, Maret 2020, (Hal. 1-9)

Berdasarkan data kedua kelompok usia sudah tergolong baik di dalam efikasi diri pada aspek strenght (kekuatan diri). Anak dengan efikasi diri pada aspek strength yang tinggi akan tekun dalam meningkatkan usahanya meski pengalaman mencoba untuk melemahkan, sehingga termotivasi untuk melakukan hal yang baik bagi dirinya.

Data tersebut didukung dari hasil pernyataan anak pada kuesioner yang telah disebarkan bahwa sebanyak $90 \%$ anak mampu menjalani terapi secara teratur sesuai dengan instruksi dokter meski kadang malas dan sebanyak 58\% anak mampu untuk mengkonsumsi obat secara teratur, walaupun anak merasa bosan. Sejalan dengan penelitian lain yang menyatakan bahwa $83,3 \%$ responden merasa bertanggung jawab terhadap sakitnya karena mereka yang lebih mengetahui kondisinya, sedangkan $16,7 \%$ responden tidak memiliki pemikiran kalau dirinya lebih bertanggung jawab karena selama ini orang-orang disekitarnya yang lebih overprotektif.

Pada penelitian ini, kekuatan diri yang dimiliki oleh setiap individu akan berbedabeda tidak dapat dinilai dari usianya meski pada beban yang sama. Efikasi diri yang tinggi cenderung memiliki aspek strength tinggi, karena individu berusaha meyakinkan diri agar tidak mudah menyerah dalam memperbaiki dan menghadapi kendala untuk menyelesaikan masalahnya. Didukung dari wawancara kepada anak bahwa banyak hal yang memotivasinya untuk menjalani pengobatannya, dipengaruhi dari lingkungan, dukungan orangtua, teman seperjuangan, komunitas dan juga anak sudah mengetahui efek yang dirasakan bila tidak menjalani pengobatannya secara rutin.

Berdasarkan data, anak yang memiliki efikasi diri tinggi pada aspek levelakan lebih mampu berusaha dan percaya diri akan kemampuan dirinya ketika dihadapkan oleh tugas dan kegiatan sekolah. Data tersebut didukung dari hasil pernyataan anak pada kuesioner yang telah disebarkan bahwa sebanyak $78 \%$ anak mampu mengerjakan tugas sekolah secara maksimal sesuai dengan kemampuan yang ia miliki, sebanyak $70 \%$ mampu

Stella, dkk., Efikasi Diri Anak Usia,... memperhatikan pelajaran dikelas dengan baik.

Kedua kelompok usia 6-12 tahun dan 1318 tahun masih berusaha untuk percaya diri dengan kemampuannya sehingga mampu menghadapi situasi yang sulit dengan berupaya mengerjakan tugas dan beraktifitas di sekolah seperti anak normal lainnya. Individu dikatakan mampu atau tidaknya dalam mengerjakan tugas yang terkait dengan prestasi belajar umumnya terjadi akibat malas belajar bukan hanya karena sakit saja.

Pada penelitian ini efikasi diri pada aspek level untuk kelompok usia 6-12tahun dan 13-18 tahun berada pada kategori tinggi, dimana responden memiliki usaha dan keyakinan untuk dapat menyelesaikan tugas sekolah yang dihadapi. Tetap ada keinginan dan semangat menyelesaikan tugasnya sebagai siswa, walaupun dengan keterbatasan fisik yang mereka miliki. Selain keyakinan diri yang muncul dari diri sendiri pemberian dukungan yang baik dari keluarga ataupun teman sekitar juga menjadi faktor yang kuat dalam terciptanya efikasi diri yang tinggi.

Berdasarkan hal diatas maka pentingnya peran perawat dalam memberikan asuhan keperawatan padaanak dengan thalasemia. Khususnya pemberian penguatan dan dukungan terhadap sakit yang dialami anak untuk membantu anak meningkatkan efikasi diri yang baik. Keterbatasan dalam penelitian ini dantaranya yaitu kesulitan mendapatkan sampel dikarenakan anak thalasemia yang melakukan tranfusi tidak dapat dipastikan ada atau tidaknya dan bila ada belum tentu sesuai dengan kriteria inklusi dalam penelitian.

\section{SIMPULAN}

Sebagian besar penderita thalasemia berusia 6-12 tahun dengan jenis kelamin perempuan, responden sebagian besar menjalani terapi $<10$ tahun dengan usia awal terdiagnosis pada usia $\leq 1$ tahun. Kelompok usia 13-18 tahun memiliki efikasi diri yang tinggi. efikasi diri pada aspek strength dan general pada usia kelompok 6-12 tahun dan 13-18 tahun sudah tergolong baik, sedangkan efikasi 
NERS: Jurnal Keperawatan, Volume 16, No. 1, Maret 2020, (Hal. 1-9)

diri tinggi dalam aspek level yaitu kelompok usia 13-18 tahun.

\section{UCAPAN TERIMAKASIH}

Terima kasih kepada seluruh staff STIK Sint Carolus dan kepada semua orang tua serta anak-anak thalasemia yang sudah membantu dalam proses penyelesaian penelitian ini dan kepada orangtua juga teman- teman atas waktu dan doa kalian semua.

\section{DAFTAR PUSTAKA}

Alwisol. (2009). Psikologi Kepribadian. Malang: UMM Press.

Anas, M. (2013). Hubungan antara dukungan keluarga dengan penerima mandiri pasien thalasemia di POPTI (Perhimpunan Orang Tua PenderitaThalasemia Indonesia) di Bandung. Diambil dari https://digilib.unpas.ac.id/files/disk1 /103/jbptunpaspp-gdlmuhammadna-5123-1-srps_-s.pdf.

Dini, M., Yeni, R., \& Yusran, N. (2014). Analisis Faktor yang Mempengaruhi Kualitas Hidup Anak Thalasemia Beta Mayor. Jurnal keperawatan indonesia, 7(1). Diambil dari https://jki.ui.ac.id/index.php/jki/artic le/download/375/499.

Dwi, S., Nunung, Supriyanto, N., \& Elva, K. (2012). Study Epidemiologi Deskriptif Thalasemia. Jurnal Kesehatan Masyarakat, 7(1), 3. Diambil dari https://journal.fkm.ui.ac.id/kesmas. $\% 0 \mathrm{~A} \% 0 \mathrm{~A}$

Friedman, H., \& Schustack, M. W. (2010). Kepribadian Teori Klasik dan Riset Modern. Jakarta: Erlangga.

Ghufron. (2014). Teori-teori Psikologi. Yogyakarta: Arruz Media.

Hackley, B. (2012). Buku Ajar Bidan Pelayanan Kesehatan Primer (Volume 2). Jakarta: EGC.

Harvina, S., \& Cut, A. (2018). Karakteristik Pasien Thalasemia Mayor di BLUD RSU Cut Mutia Aceh Utara. Jurnal Averrous, 4(2), 4-7.

Herlina, D., \& Silvia, Y. L. (2014). Gangguan Jantung Pada Anak
Penderita Thalasemia Mayor. Jurnah Kedokteran Syah Kuala, 14(13). Diambil dari www.jurnal.unsyiah.ac.id

Ilmi, S., Hasanah, O., \& Bayhakki. (2014). Hubungan Jenis Kelamin dan Domisili dengan Pertumbuhan pada anak dengan Thalasemia. Jurnal Online Mahasiswa Universitas Riau.

Kliegman. (2012). Ilmu Keperawatan Anak (15 ed.). Jakarta: EGC.

Krori. (2011). Developmental Psychology. Journal Homeopathic, 4(3), 420.

Locoparta, A. (2012). Hubungan Lama sakit terhadap kualitas hidup anak penderita thalasemia di RSUD Dr. Moewardi Fakultas Kedokteran: Universitas Sebelas Maret. Diambil dari

https://digilib.uns.ac.id/dokumen/do wnload/30453/NjQwNjY=/Hubunga n-lama-sakit-terhadap-kualitashidup-penderita-thalasemia-diRSUD-Dr-Moewardi.pdf.

Mulyani, \& Adi, F. (2011). Reaksi psikososial terhadap penyakit di kalangan anak penderita thalasemia mayor di Bandung. 16(1).

Pratiwi, A., Sawitri, E., \& Supit, D. M. (2018). Gambaran kasus anak talasemia di RSUD Abdul Wahab Sjahranie Samarinda periode 20142016. Jurnal Kedokteran Mulawarman, 4(1), 51-52.

Rahman, A. (2013). Psikologi Sosial: Integrasi Pengetahuan Wahyu dan Pengetahuan Empirik. Jakarta: Rajawali Pers.

Safitri, R., Ernawaty, J., \& Karim, D. (2015). Hubungan Kepatuhan Tranfusi dan konsumsi kelasi besi terhadap pertumbuhan anak dengan thalasemia. Jurnal Online Mahasiswa Universitas Riau, 2(2), 1474-1480. Diambil dari jom.unri.ac.id

Sriyanti, L. (2011). Pembentukan self control dalam perspektif nilai multikultural. Salatiga.

Sumiarsih, D. (2016). Kualitas Hidup Penderita Thalasemia Beta Mayor di Ruang Cempaka RSUD $d r$, Soediran Mangun Soemarso Wonogiri. Surakarta.

Yanitawati, Ali, M., \& Efri, W. (2017). Hubungan Perilaku Sakit dalam 
NERS: Jurnal Keperawatan, Volume 16, No. 1, Maret 2020, (Hal. 1-9)

Aspek Psikososial dengan Kualitas Hidup Remaja Thalasemia. Jurnal
Keperawatan BSI, 5(1), 43-45.

Diambil dari ejournal.bsi.ac.id 